\title{
Impact of COVID-19 Lockdown on Air Quality in Moscow
}

\author{
A. S. Ginzburg ${ }^{a, *}$, Corresponding Member of the RAS V. A. Semenov ${ }^{a, b}$, E. G. Semutnikova ${ }^{c, d}$, \\ M. A. Aleshina ${ }^{a, b}$, P. V. Zakharova ${ }^{e}$, and E. A. Lezina ${ }^{e}$ \\ Received July 23, 2020; revised August 6, 2020; accepted August 21, 2020
}

\begin{abstract}
The results of an analysis of changes in the atmospheric air quality in Moscow during the lockdown period and the decline in business activity caused by the COVID-19 coronavirus pandemic are presented. The observed changes in urban air pollution represent a unique experiment to assess the impact of various anthropogenic influences on the composition of atmospheric air. The influence of weather factors and transport activity on the level of pollution in the spring of 2020 is considered. The level of the main pollutants in the atmosphere decreased by 30-50\% during the period of lockdown, and a different type of changes was revealed near highways and in residential areas. This article discusses the possibilities and difficulties of using a "unique experiment" on a sharp decrease in traffic intensity in large cities to determine the contribution of various branches of the urban economy (transport, energy, industry, waste processing) to the total air pollution in large cities.
\end{abstract}

Keywords: COVID-19, lockdown, Moscow, city traffic, atmospheric pollution, air quality

DOI: $10.1134 / \mathrm{S} 1028334 \mathrm{X} 20110069$

\section{INTRODUCTION}

Natural and man-made disasters have a negative impact on the quality of life of mankind and the environment. Studying of these events creates new knowledge and technologies that can be used to prevent and mitigate the consequences of future disasters, improve the quality of life, and ensure the safety of the population.

Atmospheric air, water, and natural objects in large cities are most vulnerable to anthropogenic impact. The World Health Organization (WHO) estimates that diseases directly related to air pollution are responsible at present for 4.6 million deaths annually [1]. The anthropogenic impact is complex, since in urban agglomerations the climate, air quality, and the environment are simultaneously influenced by both global and regional natural factors (global warming, heat waves and cold snaps, etc.) and specific intra- and

\footnotetext{
${ }^{a}$ A.M. Obukhov Institute of Atmospheric Physics, Russian Academy of Sciences, Moscow, 119017 Russia ${ }^{b}$ Institute of Geography, Russian Academy of Sciences, Moscow, 119017 Russia

${ }^{c}$ Department of Natural Resources Management and Environmental Protection of Moscow, Moscow, 117198 Russia

${ }^{d}$ Moscow State University, Moscow, 119991 Russia

e State Budgetary Environmental Institution

Mosecomonitoring, Moscow, 119019 Russia

*e-mail: gin@ifaran.ru
}

extra-urban factors (building, energy, industry, transport, landfills, etc.), the assessment of the relative importance of which is a difficult task (see for example [2]). In most large cities, it is difficult to distinguish the contribution of individual pollution sources, especially for various industrial enterprises and landfills, against the background of the main source of urban air pollution-transport. The atmospheric air composition in Moscow, the sources and concentrations of atmospheric pollutants, and trends in air quality in Moscow in comparison with the largest cities in the world are given in the reports of the Department of Natural Resources Management and Environmental Protection of Moscow (see, for example, [3]).

The COVID-19 pandemic has reduced by several times city traffic on the streets of Moscow and other cities in Russia and the world, accompanied by a noticeable economic recession and a decrease in industrial emissions that pollute the atmosphere of cities, as well as to a noticeable decrease in greenhouse gas emissions with possible climatic effects [4]. Ambient air quality monitoring data objectively demonstrate a significant reduction in the content of harmful substances. In many countries, especially in the densely populated areas of China and India [5], where aerosol air pollution is especially strong, since January of this year, there has been a sharp purification of air from suspended particles and engine emissions. Thus, the COVID-19 pandemic "set up a natural experiment" on the impact of a sharp decline in city traffic on urban air quality. 


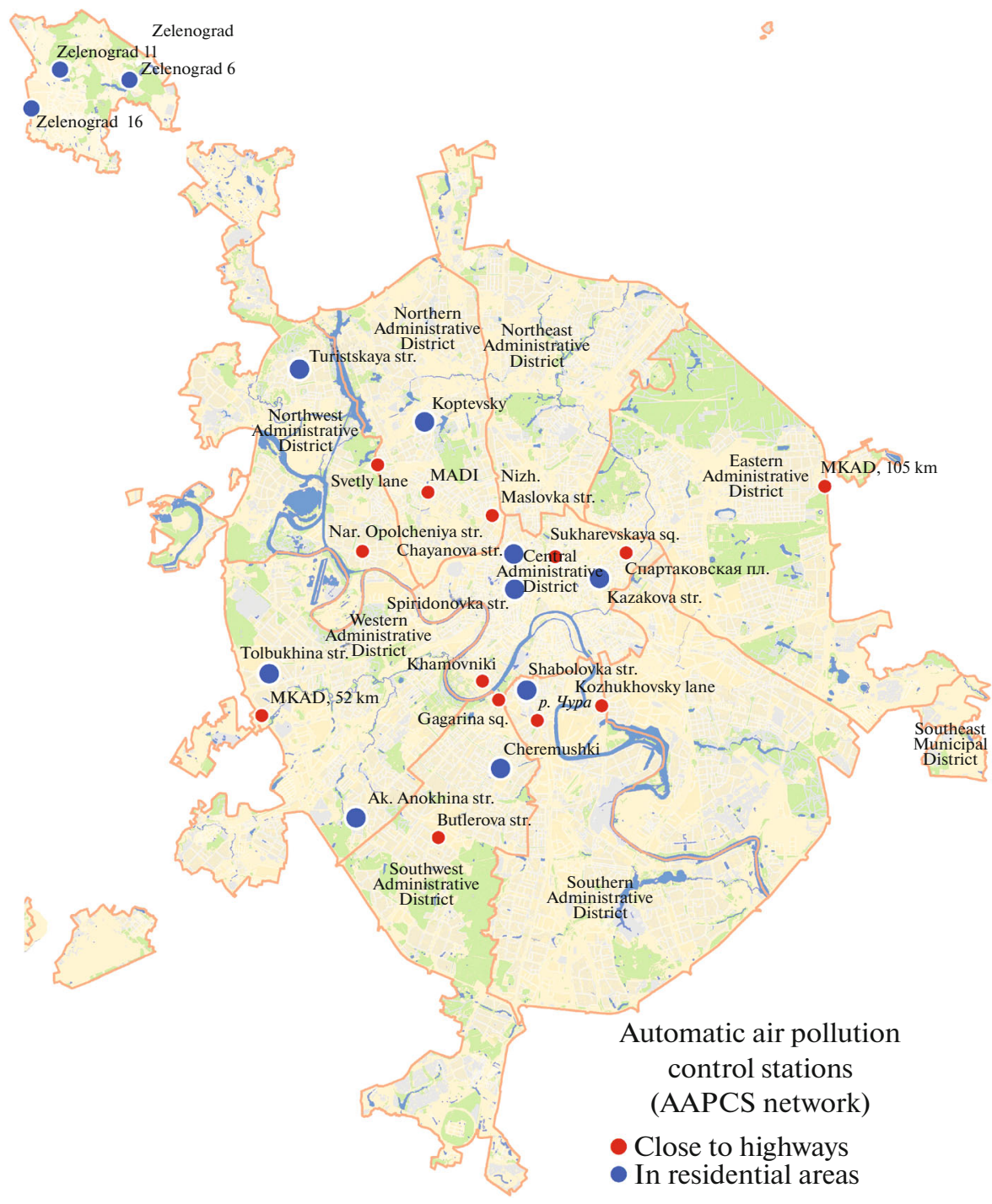

Fig. 1. Location of AAPCSs near highways and in residential areas within the boundaries of Moscow in 2011.

\section{SOURCES OF AIR POLLUTION IN MOSCOW}

The composition, concentration, and spatial-temporal distribution of the main air pollutants in Moscow are constantly monitored by automatic air pollution control stations (AAPCS network) of the State Budgetary Environmental Institution "Mosecomonitoring," then annually summarized and analyzed in reports of the Department of Natural Resources Management and Environmental Protection of the Moscow Government. According to [3], within the boundaries of modern Moscow there are more than fifty AAPCSs located near highways, in residential, natural, and mixed territories. This paper analyzes the data of AAPCSs near highways and in residential areas (Fig. 1).

Due to the AAPCS network, the concentration of pollutants in the atmosphere of Moscow is quite well known. It is much more difficult to identify the main sources of Moscow air pollution. This is due to the fact that not all sources of air pollution in Moscow are located within the city's administrative borders. At the same time, estimating emissions from various sources (transport, industry, waste) is a complex and difficult task, since the provision of data on emissions from various sectors of the urban economy is not always controlled by normative legal acts and is often a manifestation of the environmental responsibility of business. In addition, the transport and accumulation of pollutants in the city is highly dependent on specific meteorological conditions.

In Moscow, as in all large cities, the main source of pollutant emissions is motor transport, which creates a high spatial variability of pollution with a maximum near highways and a minimum in residential and suburban areas. The amount of vehicle emissions is a fully calculated value based on data on the emissions of dif- 
ferent types of vehicles under different engine operating conditions.

The main contribution to emissions of pollutants by road transport in Moscow is made by carbon monoxide (almost 2/3 of all emissions); it is a product of incomplete combustion of fuel. The concentration of carbon monoxide depends on the configuration of the road network, traffic intensity, weather conditions, and street configuration. Its average concentration in recent years has been at the level of $0.36 \mathrm{mg} / \mathrm{m}^{3}$. Approximately $20 \%$ of transport emissions are nitrogen oxides, and slightly more than $10 \%$ are volatile hydrocarbons. Suspended particle emissions are about $1 \%$ excluding emissions from road surface abrasion and tires and brake pads of cars, which range from 2500 to 5000 tons/year [3].

\section{CITY AIR DURING LOCKDOWN}

Reductions in air pollution during the COVID-19 restrictions have been observed in many cities and regions of the world (see, for example, [4-7] and other publications in spring and summer 2020). Most of these publications are based on satellite observations of atmospheric gases (mainly nitrogen dioxide). Ground-based measurements of the dynamics of atmospheric pollution during lockdown have not yet been analyzed sufficiently. Only a few publications can be noted, for example [7], where the aerosol content was compared before and during lockdown in Almaty according to data from one station in the city center.

In Moscow, from early April to mid-May 2020, mainly reduced concentrations of pollutants were observed. This could have been due to the significant decrease in the traffic intensity of vehicles, emissions from which in a normal situation make up more than $90 \%$ of the total emissions of pollutants into the atmosphere of Moscow. According to the Moscow Department of Transportation, the Moscow motorway network workload in April 2020 was approximately four times less than in April 2019 [8].

The average concentrations of pollutants in April 2020 were lower than the average for the previous three years. At the same time, the decrease in air pollution manifests itself in different ways near highways and in residential areas (Table 1).

Table 1 shows an interesting fact that characterizes the transport and deposition of pollutants in the city's atmosphere and which shows that during the quarantine and the corresponding restriction of transport activity, the air inside residential areas was purified stronger than near highways.

It should be noted that it is particularly difficult to assess the impact of lockdown on air quality in Moscow in the second quarter of 2020. First, in the spring, after snow melt, an increase in the content of atmosphere pollutants and especially suspended particles usually happens in the Moscow Region. In 2020, there
Table 1. Decrease in the average concentration of the main pollutants in the atmospheric air of Moscow in April 2020 compared to the average level in recent years (in percent) according to the data of the State Budgetary Environmental Institution "Mosecomonitoring"

\begin{tabular}{l|c|c}
\hline \multicolumn{1}{c|}{ Pollutant } & Close to highways & In residential areas \\
\hline Carbon monoxide & $-28 \%$ & $-38 \%$ \\
Nitrogen dioxide & $-33 \%$ & $-55 \%$ \\
Nitrogen oxide & $-63 \%$ & $-66 \%$ \\
Suspended particles & $-17 \%$ & $-28 \%$ \\
\hline
\end{tabular}

was an extremely snowless winter, as a result of which the seasonal trend of aerosol content in the Moscow air in the first half of the year could have been atypical. Second, at the end of March 2020, there was a period of a positive pressure anomaly, which led to a strong development of unfavorable meteorological conditions that contributed to the accumulation and a multiple increase in the content of pollutants in the surface layer of the atmosphere. This was followed by a decrease in pressure in April and the first half of May. Thus, the pressure trends from March to May were generally similar to the dynamics of the transport activity index in Moscow. Due to the meteorological features of spring 2020, in order to identify the causes of air quality changes during lockdown relative to the average data obtained by the State Budgetary Environmental Institution "Mosecomonitoring" for the period 2017-2019, a thorough analysis is required.

Changes in the average daily concentrations of pollutants in Moscow in March-May 2020 relative to the average values for 2017-2019 are shown in Fig. 2. The sea level air pressure values are also shown. A sharp short-term jump in concentrations for March 27-28, as mentioned above, is associated with a powerful positive pressure anomaly and unfavorable conditions for dispersion of impurities. Despite the meteorological features of the spring of 2020, one can note the dependence of the content of a number of pollutants and, first of all, carbon monoxide on the decrease in transport activity in Moscow (transport activity was estimated according to the data of the Moscow Department of Transport [8]).

During the quarantine period, the Moscow Department of Transport promptly published data on the intensity of passenger traffic in public and private transport in the city. Since the passenger traffic of public transport is measured in millions of people transported per day, the data on personal transport flows were given in the same units. Data on public transport passenger flows are not very informative for the purposes of this study, since this transport includes not only buses, the emissions of which pollute the urban atmosphere, but also electrified transport-subway, electric trains, trams, and trolleybuses. Due to the predominant number of personal vehicles in the 

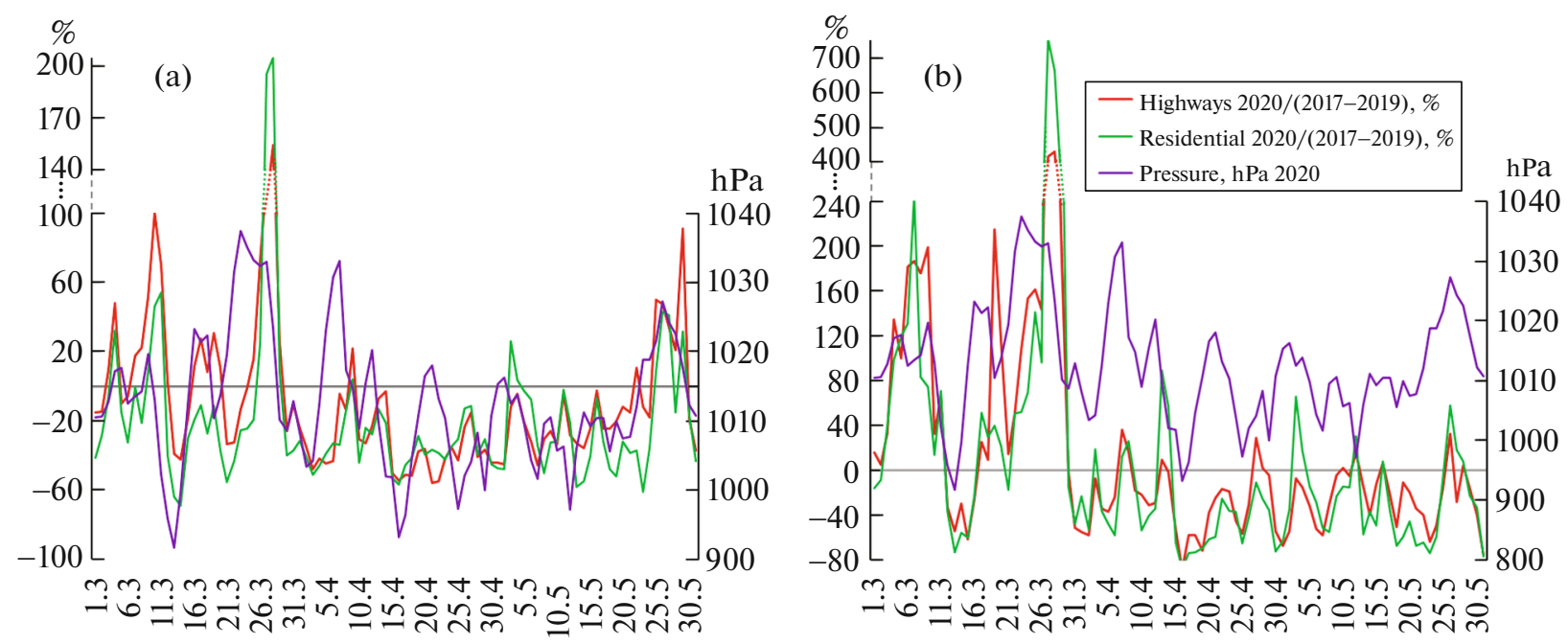

Fig. 2. Change in (a) CO and (b) $\mathrm{PM}_{10}$ concentrations in the spring of 2020 compared to the average values of 2017-2019 (in \%) for AAPCSs near highways (red lines) and in residential areas (green lines). The purple line shows the atmospheric pressure at sea level according to the Balchug weather station (in hPa).

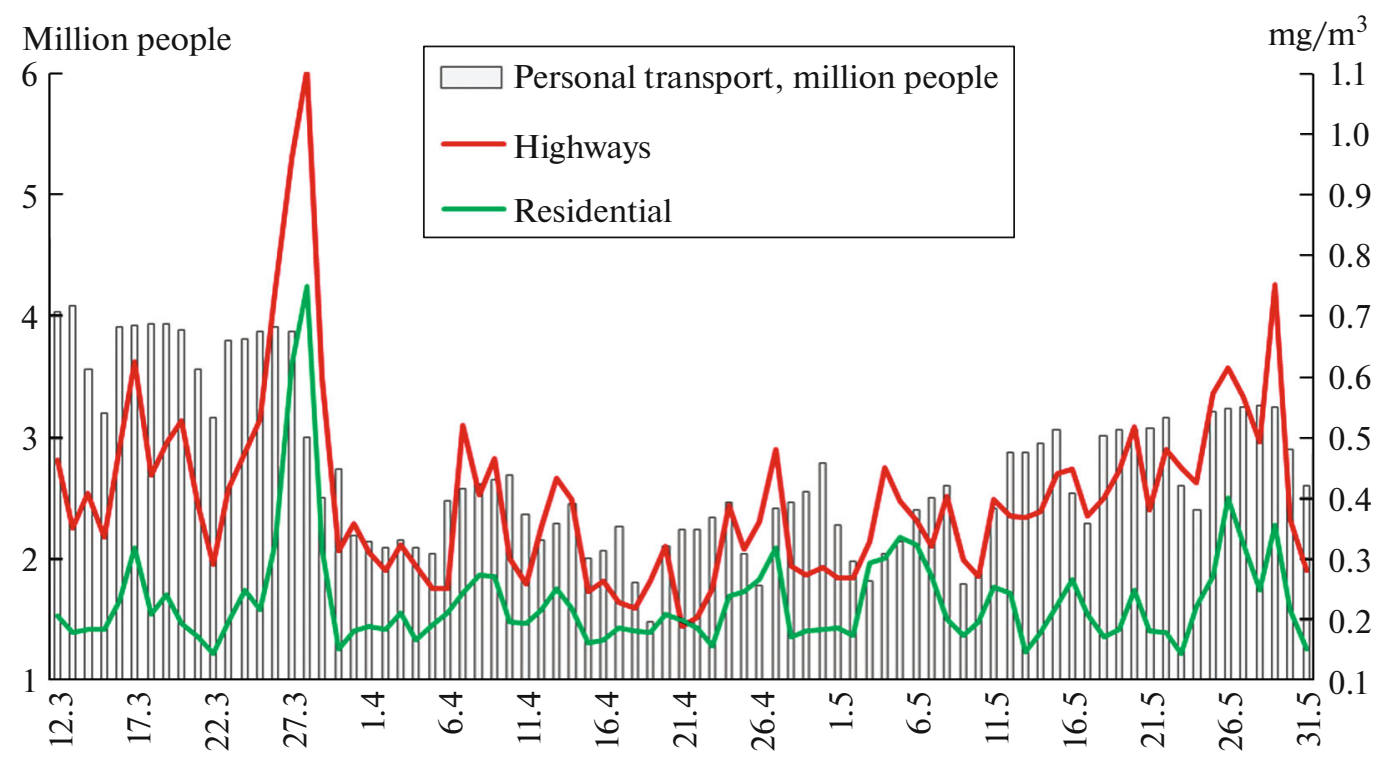

Fig. 3. CO concentrations trend in spring 2020 for stations near highways (red lines) and in residential areas (green lines). The dynamics of personal transport passenger traffic (million people/day) is shown in gray.

total number of cars on the roads of Moscow (according to Mosgortrans and the Traffic Management Center (TMC), the number of passenger cars exceeds the number of buses by more than 100 times) and the proportionality of the number of passengers to the number of cars, data on passenger traffic in terms of personal transport can be used as an index of general transport activity in the city.

In March 2020, before the lockdown, the CO content near highways significantly exceeded its content in the air of residential areas. In April and early May, the $\mathrm{CO}$ content in the city as a whole decreased sig- nificantly, while its concentrations near highways and in residential areas became closer to each other. Since the middle of May, as the restrictions were removed and transport activity increased, the $\mathrm{CO}$ concentration began to grow, and it increased near highways much faster than in residential areas (Fig. 3).

The importance of taking into account weather conditions for the interpretation of air purification in cities during quarantine has also been noted by American scientists [9]. According to them, the noticeable decrease in nitrogen dioxide $\left(\mathrm{NO}_{2}\right)$ content observed from satellite data in March-April 2020 in different 
cities of the United States depends significantly on the precipitation regime in the corresponding regions of the country. Similar conclusions were obtained for pollution in Chinese cities, where extremely high levels of pollution associated with weather conditions were observed against the background of a general decrease in the level during lockdown [5].

\section{DISCUSSION AND CONCLUSIONS}

An analysis of the improvement in air quality in Moscow during the restrictions imposed by COVID-19 showed a difference in the impact of a decrease in economic activity on the content of various atmospheric pollutants near highways and in residential areas of the city.

At the same time, difficulties were found in accounting for weather conditions for interpreting urban air purification during lockdown and comparing observations in the spring seasons of various years.

Further analysis of changes in the content of atmospheric pollutants in the context of a sharp decline in economic activity will help to improve methods for assessing the contribution of various sources to air pollution and the impact of reduced traffic on air quality.

For reliable quantitative assessments of the effect of reducing traffic and reducing economic activity on the content of pollutants in the urban atmosphere, it is necessary to take an inventory of the composition and amount of emissions of gas and aerosol pollutants into the atmosphere from various types of industrial enterprises, energy facilities, trade (including public catering facilities), everyday services, and other urban sectors, as well as landfills and waste processing enterprises, taking into account the specifics of various cities in Russia, such as Moscow, St. Petersburg, Omsk, and Chelyabinsk, where the ratio of emission sources is different and at the same time there is a sufficiently developed observation network.

The results of such a study can be used for planning the "green" development of the urban economy and environmental "improvement" of industrial enterprises.

\section{FUNDING}

This work was supported by the Russian Science Foundation, project no. 19-17-00242, and the Russian Foundation for Basic Research, project no. 20-05-00254.

\section{REFERENCES}

1. A. J. Cohen, M. Brauer, R. Burnett, et al., Lancet 389, 1907-1918 (2017).

2. O. Popovicheva, S. Padoan, J. Schnelle-Kreis, et al., Aerosol Air Qual. Res. 20, 702-719 (2020).

3. Environment State in Moscow in 2018, Ed. by A. O. Kul'bachevskii (Moscow Dep. Nat. Resour. Manage. Environ. Protect.; Inst. Urban Plann. Syst. Dev.; Studio Arrow JSC, Moscow, 2019) [in Russian].

4. T. L. Schindler, Reductions in Nitrogen Dioxide Associated with Decreased Fossil Fuel Use Resulting from COVID-19 Mitigation. https://svs.gsfc.nasa.gov/4810.

5. P. Wang, K. Chen, S. Zhua, P. Wang, and H. Zhang, Resour., Conserv. Recycl. 158, 104814 (2020). https://doi.org/10.1016/j.resconrec.2020.104814

6. C. Le Quéré, R. B. Jackson, M. W. Jones, et al., Nat. Clim. Change 10, 647-653 (2020). https://doi.org/10.1038/s41558-020-0797-x

7. A. Kerimray, N. Baimatova, O. P. Ibragimova, et al., Sci. Total Environ. 730, 139-179 (2020).

https://doi.org/10.1016/j.scitotenv.2020.139179

8. https://tlgrm.ru/channels/@DtRoad.

9. Q. Schiermeier, Nature 580, 313 (2020).

Translated by V. Selikhanovich 